\title{
Making business scents: how to harvest incense sustainably from the globally threatened lansan tree Protium attenuatum
}

\author{
Jennifer C. Daltry, Alfred Prospere, Adams Toussaint \\ Jana Gengelbach and Matthen N. Morton
}

\begin{abstract}
Wild tree resins generate billions of dollars in revenue annually but many species face extinction. The lansan tree Protium attenuatum has disappeared across most of its range as a result of overexploitation for its valuable oleoresin, which is used as incense. This study in Saint Lucia aimed to determine whether lansan resin could be harvested sustainably. Over 34 months, 298 trees were tapped using 10 experimental methods, and compared with 74 controls. Significantly more resin was produced by tapping the same trees repeatedly, tapping trees with a wider girth, cutting the same part of the trunk repeatedly, and, in particular, spraying diluted sulphuric acid on the cut. Applying 5 and $30 \%$ sulphuric acid boosted yields by 58 and $134 \%$, respectively, without negative impacts on tree growth, condition or mortality. In contrast, traditional methods used by local tappers were destructive, causing greater decay and infection, slower growth rates and increased mortality. Results show tappers can obtain more resin and maintain healthy populations by tapping mature trees of $\geq 20 \mathrm{~cm}$ diameter at breast height, using only one shallow cut per tree (refreshed every 2 weeks) and applying weak sulphuric acid solution. A blind survey found consumers could not distinguish between incense produced with or without this stimulant. A national management plan has been devised whereby tappers will be licensed and trained in the optimal method and granted their own forest coupes to manage under Forestry Department supervision. The methods and findings may guide the sustainable use and conservation of other resin-producing trees.
\end{abstract}

\footnotetext{
JenNifer C. DALtry (Corresponding author) Fauna \& Flora International, Jupiter House, Station Road, Cambridge, CB1 2JD, UK

E-mail jenny.daltry@fauna-flora.org

Alfred Prospere and Adams Toussaint Forestry Department, Ministry of Sustainable Development, Energy, Science \& Technology, Gabriel Charles Forestry Complex, Union, Castries, Saint Lucia

Jana Gengelbach University for Sustainable Development, Eberswalde, Germany

Matthew N. Morton Durrell Wildlife Conservation Trust, c/o Forestry Department, Ministry of Sustainable Development, Energy, Science \& Technology, Gabriel Charles Forestry Complex, Union, Castries, Saint Lucia

Received 20 June 2014. Revision requested 27 August 2014.

Accepted 25 November 2014. First published online 25 March 2015.
}

Keywords Burseraceae, Lesser Antilles, non-timber forest products, Protium, resin, Saint Lucia, sustainable livelihoods

\section{Introduction}

Ton-timber forest products (NTFPs) are no longer re1 garded as resources of only minor significance; they are now seen to offer potential benefits for rural development and the conservation of forests (Peters et al., 1989; Schwartzman et al., 2000; Higgins-Zogib et al., 2010). Arnold \& Ruíz-Pérez (2001) identified three main strands linking NTFPs to forest conservation: NTFPs contribute to the livelihoods and welfare of people living in and adjacent to forests; commercial harvest of NTFPs adds to the perceived value of the forest and hence the incentive to preserve it; and NTFP exploitation is less destructive than logging and other forest uses and can therefore provide a sound base for sustainable forest management. Bolstered by these premises, authorities in many protected areas permit local communities to harvest nuts, leaves, bark, resin, roots and other plant products, even where hunting and timber extraction are forbidden (Coad et al., 2008). Some researchers believe traditional practices have 'inherently assured the sustainable harvesting of NTFPs' (Ahmad, 2003) but others have raised concerns that even customary extraction methods can endanger certain species and damage the forest (Ndangalasi et al., 2007; Stanley et al., 2012).

Tree resins are among the most sought-after NTFPs because they are non-perishable and have a relatively high value per unit weight (Newton et al., 2011). Copals, dammars and other hard resins are used in varnishes, adhesives, paints, plastics and fireworks, whereas the softer, odoriferous oleoresins, such as frankincense, turpentine, copaiba and myrrh, are used for medicinal purposes and in incense (Langenheim, 2003). Their global economic value is considerable: agarwood oleoresin alone generates annual revenue of USD 6-9 billion (Akter et al., 2013). Overexploitation has resulted in many lucrative species becoming threatened with extinction, however, including most species of agarwood (Aquilaria spp.) and frankincense trees (Boswellia spp.) that have been assessed (IUCN, 2014). Researchers in this field have focused primarily on resin 
production and trade (e.g. Johnson, 1998; Tadesse et al., 2004; Ali et al., 2009) rather than on the species' ecology or the impacts of exploitation.

One of the lesser-known species exploited by the resin industry, the lansan tree Protium attenuatum (Burseraceae), is endemic to the mid-elevation rainforests of the Eastern Caribbean, specifically Dominica, Guadeloupe, Grenada, Martinique, Saint Christopher and Nevis, Saint Lucia, and Saint Vincent and the Grenadines (Howard, 1988; Rollet, 2010). Although currently categorized as Data Deficient on the IUCN Red List (WCMC, 1998), more recent research indicates the lansan should be categorized as Endangered. Few lansan trees remain on Martinique and Guadeloupe, and surveys in 2014 failed to find any on Grenada or Saint Vincent. Only Saint Lucia and Dominica are confirmed to hold substantial populations (AP, unpubl. data). In Saint Lucia the tree's aromatic fruits are an important food source for wild animals, including the Vulnerable Saint Lucia amazon Amazona versicolor (Collar et al., 1992).

Lansan trees are still abundant in Saint Lucia's rainforests but face increasing pressure from uncontrolled extraction of their aromatic oleoresin (Toussaint, 2009). Called lansan or l'encens, the white exudate is obtained by slashing the bark, and coagulates and hardens before being scraped off with a knife approximately 2 weeks later. Dried lansan is burned as incense at religious ceremonies, to treat various ailments (e.g. sinus congestion and arthritis), as a mosquito repellent, and to ward off evil spirits (Slane, 1987; Broome et al., 2007). In Saint Lucia, lansan is bought by at least $60 \%$ of Saint Lucians and by almost every church; it is also exported overseas (Morton, 2009; Toussaint, 2009). Martinique is the largest market, having driven its own stocks to near extinction (Palli, undated; Rollet, 2010). Timber from the lansan tree has almost no economic value because it splits easily and succumbs quickly to insects and decay (Questel, 1951; Longwood, 1962).

In Saint Lucia, resin is harvested by full-time tappers, for whom it constitutes the main source of income, and by a growing number of opportunistic harvesters, who do so for extra cash. Most lansan trees are in protected forests (Fig. 1), where entry is prohibited without a permit. Illegal tapping is rife, however, and putatively linked to lack of job opportunities in the banana industry (Toussaint, 2009). Tappers use a variety of cutting tools and techniques, and each tree may be visited and cut multiple times by different tappers, often leading to disputes when tappers take resin from cuts made by others. Toussaint (2009) reported increased tree mortalities and poorer regeneration in heavily exploited areas.

The destruction of lansan trees by tappers posed a dilemma for the Government of Saint Lucia, which has a responsibility to conserve the largest remaining population of lansan trees, notwithstanding the species'

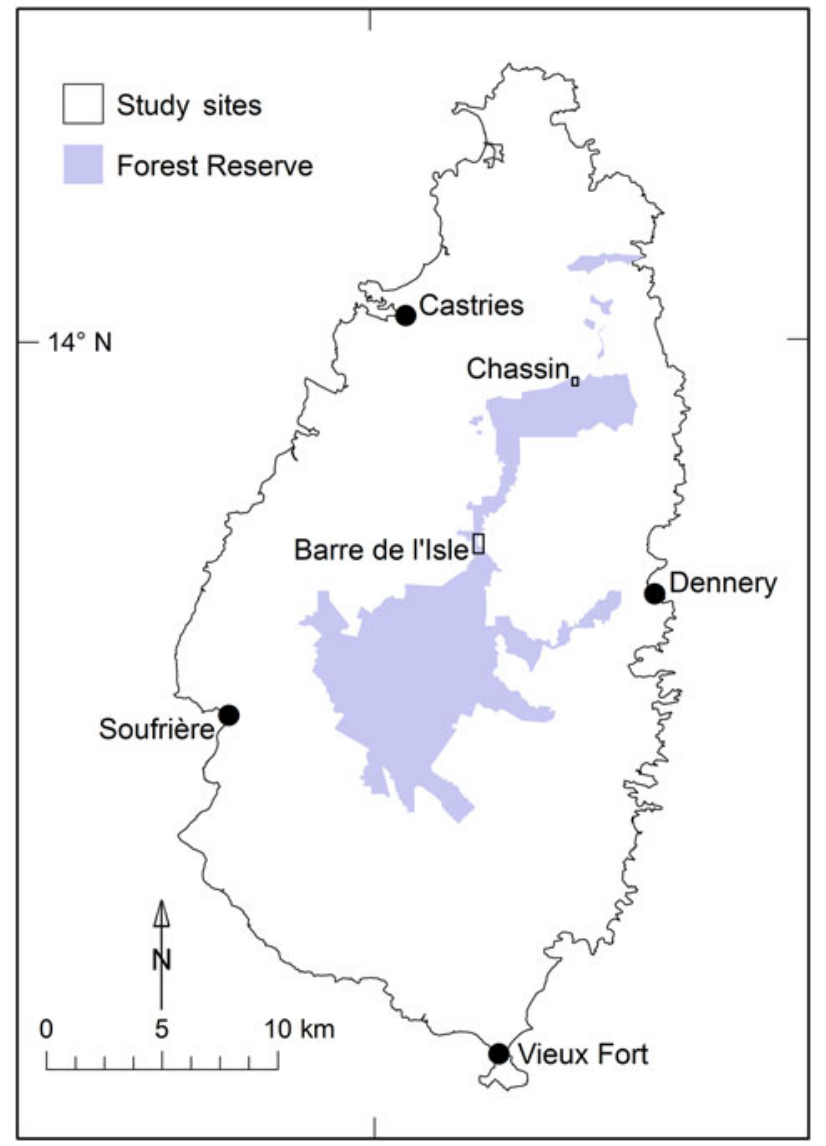

Fig. 1 Locations of forest reserves and major towns in Saint Lucia. The rectangles show the locations of the study sites in Barre de l'Isle and Chassin Forests.

cultural and economic importance and that the tappers who harvest it typically come from the poorest sectors of rural society. There have been calls for lansan to be harvested sustainably (e.g. van Eynde, 2009; Morton, 2009), but can resin be extracted without debilitating the wild stocks?

Here we describe an experimental study to (1) measure the quantity of resin produced from lansan trees of different sizes, using conventional and alternative tapping techniques, (2) evaluate and compare the effects of various tapping methods on the health and survival of lansan trees, and (3) determine whether consumers prefer resin harvested using traditional or alternative tapping techniques. The primary purpose was to guide the development of a sustainable harvesting programme for lansan trees in Saint Lucia. The secondary purpose was to design a methodology for evaluating extraction methods that could potentially be applied to other resin-producing trees.

One notable innovation that we tested was the application of sulphuric acid solution to cuts in the tree's cambium layer. A variety of chemical stimulants, including sulphuric acid, hydrochloric acid and the herbicide Paraquat (Tsoumis, 1992; Nair, 2003), are used in the 
extraction of resins and gums from trees but none of these had been tested on lansan trees.

\section{Study area}

Saint Lucia $\left(617 \mathrm{~km}^{2}\right)$ is a Small Island Developing State in the Lesser Antilles (Eastern Caribbean), with a population of 165,595 (2010 census). Lansan trees occupy the lower montane forests (Graveson, 2009), mostly within an area of c. 6,975 ha within the protected forest reserves (Daltry, 2009; Toussaint, 2009). Lower montane forest occurs at 100-680 m altitude in Saint Lucia (Graveson, 2009) and most lansan trees are concentrated at $300-550 \mathrm{~m}$. These are wet, evergreen forests, with annual precipitation of 2,000-4,000 mm (CCA, 1991).

To examine the effects of extracting resin using traditional and alternative tapping methods, two sites were selected in the forest reserves where lansan trees are locally abundant (Fig. 1). (1) The Barre de l'Isle Forest is near the centre of Saint Lucia, at 275-365 m altitude. The survey area was only a few hundred metres from a Forestry Department station and checkpoint, and lansan trees in this area were largely untouched. The study trees were accessed along an existing hiking trail. (2) In Chassin Forest (altitude 160-335 m), in north-east Saint Lucia, lansan trees are harvested illegally by tappers from the village of Chassin. Access to the Chassin study area was via the tappers' foot-trails, starting from the Chassin Sky Rides, a tourist attraction on the edge of the forest reserve.

\section{Methods}

\section{Barre de l'Isle Forest}

This forest was used for an experimental study of the impacts of various tapping methods on resin yield and the health and survival of trees. We selected 298 healthy lansan trees in four size classes: small $(15.0-19.9 \mathrm{~cm}$ diameter at breast height, DBH), medium (20.0-24.9 cm DBH), large $(25.0-29.9 \mathrm{~cm} \mathrm{DBH})$ and very large $(\geq 30.0 \mathrm{~cm} \mathrm{DBH})$. None had been tapped previously, judging from the absence of scars on their trunks. Controls (X) and nine tapping methods (A-I, Table 1) were assigned randomly to trees within each size class. Only very large trees were subjected to wide-faced tapping $(G)$, as this was considered too invasive for smaller trees. Groups A-G were visited and tapped every 2 weeks for 17 months, during October 2010-March 2012. Groups H and I were tapped every 2 weeks during March 2011-March 2012 (these were added following a review of the preliminary findings from these techniques, using 20 large and very large trees that had not been tapped previously). Every tree was labelled with a numbered tag and had one treatment assigned to it throughout the study. Visits were conducted every 2 weeks, the interval used by local tappers to allow resin to harden fully before collection.

Of the treatments tested, B, C, H, and especially A and E are extraction methods traditionally used by lansan collectors in Saint Lucia. Using a resin stimulant (30\% sulphuric acid solution in treatments D, F and G, 5\% sulphuric acid solution in treatment I) was a new innovation.

On every 2-weekly visit to every tree all resin that had coagulated around the cut was scraped carefully into an individual clear plastic bag, dried and weighed. To determine how tapping treatments affect tree growth and condition, a suite of variables were recorded from all of the Barre de l'Isle study trees before, during and after the experiment (Table 2).

\section{Chassin Forest}

In Chassin Forest we assessed the impacts of customary protocols followed by local tappers, using untapped lansan trees at the site as experimental controls. At random we selected 38 trees with signs of recent cuts, and 36 trees that had never been tapped (unmarked), in the four size classes (small, medium, large and very large; Table 1). Many of the tapped trees showed signs of having been tapped multiple times prior to the study, and those that appeared unhealthy or broken were rejected. Trees were inspected every 2 weeks for 13 months, during February 2011-March 2012, with a final appraisal in August 2013. Their condition was evaluated using the same variables as the first site (Table 2). We did not collect resin from the tapped trees, to avoid discouraging the dozen or more tappers from operating in this area. The tappers were not informed the study was taking place nor advised to change their usual routines. The lansan trees were not tagged, to avoid revealing which ones were under observation.

\section{Consumer survey}

A simple blind experiment was carried out to gauge whether experienced consumers could detect any differences between the resin produced with or without $30 \%$ sulphuric acid stimulant. Two samples of lansan from Barre de l'Isle (one produced without stimulant, pooled from treatments $\mathrm{A}, \mathrm{B}, \mathrm{C}$ and $\mathrm{E}$, and one with stimulant, pooled from treatments D, F and G) were given to seven Roman Catholic churches in seven parishes. The priests, who were accustomed to using lansan as incense, were not informed which sample was which. They were asked to judge the samples based on ease of burning, how well the smoke rose, scent and overall quality, scoring each variable on a scale from 1 (very poor) to 5 (very good). 
TABle 1 Tapping treatments applied to lansan trees Protium attenuatum in the Barre de l'Isle and Chassin Forests of Saint Lucia (Fig. 1), with description and sample size.

\begin{tabular}{|c|c|c|c|}
\hline Code & Treatment & Description & $\begin{array}{l}\text { Sample } \\
\text { size }\end{array}$ \\
\hline \multicolumn{4}{|c|}{ Barre de l'Isle Forest } \\
\hline $\mathrm{X}$ & Control & No cuts or other forms of intervention & 38 \\
\hline A & New cuts & $\begin{array}{l}\text { A pair of shallow horizontal cuts was made in the bark with a sharp knife, penetrating no } \\
\text { deeper than the cambium layer. New pairs of cuts were made higher up the trunk every } \\
2 \text { weeks. }\end{array}$ & 38 \\
\hline B & Standard same cut & $\begin{array}{l}\text { A single horizontal cut was made in the trunk } 1.3 \mathrm{~m} \text { above the ground, penetrating no } \\
\text { deeper than the cambium layer. The cut wound was cleared of resin \& reopened every } \\
2 \text { weeks. }\end{array}$ & 40 \\
\hline $\mathrm{C}$ & Deep same cut & $\begin{array}{l}\text { A single deep horizontal cut was made in the trunk } 1.3 \mathrm{~m} \text { above the ground, penetrating } \\
\text { into the sap wood beneath the cambium layer. The cut wound was cleared of resin } \& \\
\text { reopened every } 2 \text { weeks. }\end{array}$ & 39 \\
\hline $\mathrm{D}$ & $\begin{array}{l}\text { Standard same cut with } \\
\text { stimulant }\end{array}$ & $\begin{array}{l}\text { The same as B but after reopening the horizontal cut, the wound was sprayed with a mist of } \\
30 \% \text { sulphuric acid }\left(\mathrm{H}_{2} \mathrm{SO}_{4}\right) \text { solution, using one pass of a } 1.5 \mathrm{l} \text { spray can held c. } 15 \mathrm{~cm} \text { from } \\
\text { the cut. }\end{array}$ & 38 \\
\hline $\mathrm{E}$ & Narrow-face tapping & $\begin{array}{l}\text { A horizontal strip of bark, } 2 \mathrm{~cm} \text { high } \& 4 \mathrm{~cm} \text { wide, was removed. Every } 2 \text { weeks, a } 2 \mathrm{~cm} \text { strip } \\
\text { of bark was removed above \& adjacent to the first streak. }\end{array}$ & 38 \\
\hline $\mathrm{F}$ & $\begin{array}{l}\text { Narrow-face tapping with } \\
\text { stimulant }\end{array}$ & $\begin{array}{l}\text { The same method as E, except the fresh wound was sprayed with a mist of } 30 \% \text { sulphuric } \\
\text { acid solution. }\end{array}$ & 38 \\
\hline G & $\begin{array}{l}\text { Wide-face tapping with } \\
\text { stimulant }\end{array}$ & $\begin{array}{l}\text { A horizontal strip of bark } 2 \mathrm{~cm} \text { high } \& 10 \mathrm{~cm} \text { wide was removed across the width of the tree, } \\
\text { just above the gutter, to cause resin to flow. The wound was sprayed with a mist of } 30 \% \\
\text { sulphuric acid solution. Every } 2 \text { weeks another } 2 \times 10 \mathrm{~cm} \text { strip of bark was removed above } \& \\
\text { adjacent to the first streak } \& \text { sulphuric acid solution was applied again. This treatment was } \\
\text { applied only to very large trees }(\geq 30.0 \mathrm{~cm} \mathrm{DBH}) \text {. }\end{array}$ & 9 \\
\hline $\mathrm{H}$ & Many new cuts & $\begin{array}{l}\text { Similar to A but with six random cuts made every } 2 \text { weeks in different parts of the trunk. No } \\
\text { stimulant applied. This treatment was applied only to large }(25.0-29.9 \mathrm{~cm} \mathrm{DBH}) \& \text { very } \\
\text { large }(\geq 30.0 \mathrm{~cm} \mathrm{DBH}) \text { trees. }\end{array}$ & 10 \\
\hline I & $\begin{array}{l}\text { Standard same cut with } \\
\text { weak stimulant }\end{array}$ & $\begin{array}{l}\text { The same as D but using only } 5 \% \text { sulphuric acid solution sprayed on the cut. This treatment } \\
\text { was applied only to large }(25.0-29.9 \mathrm{~cm} \mathrm{DBH}) \text { \& very large }(\geq 30.0 \mathrm{~cm} \mathrm{DBH}) \text { trees. }\end{array}$ & 10 \\
\hline \multicolumn{4}{|c|}{ Chassin Forest } \\
\hline $\mathrm{X}$ & Control & $\begin{array}{l}\text { Trees showing no signs of having been tapped. These remained untouched for the duration } \\
\text { of the study. }\end{array}$ & 36 \\
\hline $\mathrm{T}$ & Tapped by tappers & $\begin{array}{l}\text { Trees tapped by local tappers using their chosen methods without any direction or influ- } \\
\text { ence from the research team. }\end{array}$ & 38 \\
\hline
\end{tabular}

TABLE 2 Variables measured as indicators of tree condition. In Barre de l'Isle measurements were made for every study tree at the start of the tapping experiment (October 2010 for treatment groups X and A-G; May 2011 for treatment groups $\mathrm{H}$ and I), at several intervals during the experiment (October 2010-March 2012), and in July 2013 (16 months after the experiment ended). In Chassin measurements were recorded in February 2011, August 2011, March 2012 and July-August 2013. Where possible, variables were recorded by AT and AP for consistency.

\begin{tabular}{|c|c|}
\hline Variable & Description \\
\hline Tree growth & $\begin{array}{l}\text { DBH measured in } \mathrm{cm} \text { using a diameter tape, } 1.3 \mathrm{~m} \text { above the ground (on the uphill side if the tree was on a slope). Growth } \\
\text { rate was calculated as percentage increase in girth since the beginning of the study. The } 1.3 \mathrm{~m} \text { height was marked using } \\
\text { spray paint to ensure girth was always measured in the same part of the trunk. }\end{array}$ \\
\hline $\begin{array}{l}\text { Crown } \\
\text { health }\end{array}$ & $\begin{array}{l}\text { Methods followed Synott (1979); crown quality was scored as } 5 \text { (perfect: wide, circular \& symmetrical), } 4 \text { (good: with only } \\
\text { minor defects in symmetry or a few dead tips), } 3 \text { (tolerable: distinctly asymmetrical or thin), } 2 \text { (poor: extensive die-back \& } \\
\text { strong asymmetry, but probably capable of surviving), } 1 \text { (very poor: degenerating, damaged \& probably incapable of } \\
\text { supporting growth) \& } 0 \text { (dead). }\end{array}$ \\
\hline Termites & The number of termite tunnels (including those with a partial roof) on the trunk at $1.3 \mathrm{~m}$ above the ground. \\
\hline Cankers & $\begin{array}{l}\text { The number of cankers (areas of dead \& blistered bark) protruding at least } 2 \mathrm{~cm} \text { from the surface of the trunk at } 0-2 \mathrm{~m} \\
\text { above the ground. }\end{array}$ \\
\hline Fungi & $\begin{array}{l}\text { The presence/absence of visible fungi (but not lichens) on the trunk at } 0-2 \mathrm{~m} \text { above the ground was recorded as } 1 \text { (visible } \\
\text { mould or fungal caps present) or } 0 \text { (no sign of mould or fungal caps). }\end{array}$ \\
\hline Cavities & $\begin{array}{l}\text { The number of holes in the wood (not including cuts made by tapping) at } 0-2 \mathrm{~m} \text { above the ground in each of three size } \\
\text { categories: small }(<10 \mathrm{~cm} \text { long), medium }(10-20 \mathrm{~cm}) \text { \& large }(>20 \mathrm{~cm}) \text {. }\end{array}$ \\
\hline
\end{tabular}




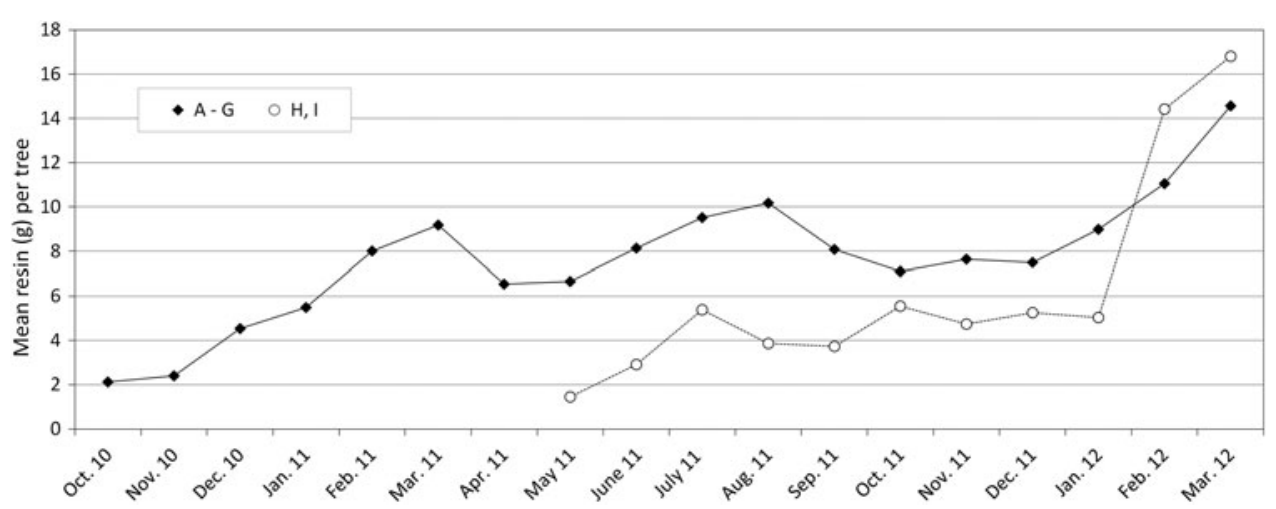

FIG. 2 Variation in mean resin yield (dry mass) across all treatment groups in the Barre de l'Isle Forest over time. Trees were tapped every 2 weeks from October 2010 for treatments $A-G(n=240)$ and from May 2011 for treatments $\mathrm{H}$ and $\mathrm{I}(\mathrm{n}=20)$.

\section{Data analysis}

Descriptive statistics and Mann-Whitney tests, Pearson's tests and Wilcoxon signed rank tests were conducted using XLSTAT v. 2013.1.01 (Addinsoft, Paris, France). To evaluate possible causes of tree mortality at the Barre de l'Isle site, partial Mantel matrix association tests were conducted using software developed by Roger S. Thorpe, to partial out the effects of collinearity between variables (Legendre \& Fortin, 1989). Trees were organized into 35 groups according to treatment (e.g. X, A, B, C) and girth $(\mathrm{DBH})$, and mortality was measured as the proportion of each group that had died by July 2013 . Seven variables putatively associated with mortality (DBH, tapping treatment, lansan yield, termites, cavities, cankers, crown health; Table 2) were tested simultaneously with a partial Mantel test using 10,000 randomizations. Statistical significance was at $\mathrm{P}<0.05$ after applying a sequential Bonferroni correction (Rice, 1989), although this may be overly cautious (Moran, 2003).

\section{Results}

At the start of the study, mean DBH of the 298 trees in the Barre de l'Isle Forest was $26.15 \pm$ SD $7.84 \mathrm{~cm}$ (range 15.0-59.8 $\mathrm{cm}$ ) and mean DBH of the 74 trees in the Chassin Forest was $26.90 \pm$ SD $10.02 \mathrm{~cm}$ (range 16.0-64.0 cm). Local tappers in the Chassin Forest used a variety of techniques, including narrow-face tapping and multiple horizontal or diagonal cuts, but did not apply any stimulant. Individual trees were often found cut using two or more cutting methods, suggesting more than one tapper had worked on them.

\section{Quantity of resin produced (Barre de l'Isle only)}

Data from all tapped trees in the Barre de l'Isle Forest revealed a highly significant correlation between quantity of lansan produced and tree size (DBH) (Pearson's correlation coefficient $(r)=0.298, \mathrm{P}<0.0001)$. Across all treatment classes very large trees $(\geq 30.0 \mathrm{~cm} \mathrm{DBH})$ typically produced

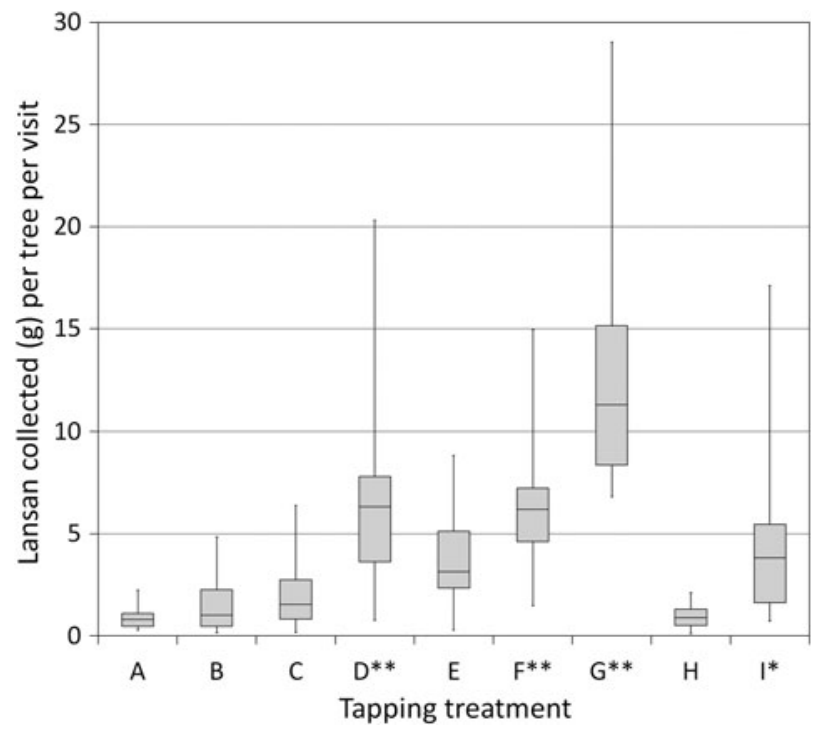

FIG. 3 Mean resin yield (dry mass) from various tapping methods, over 16 2-weekly harvests, from trees $\geq 25 \mathrm{~cm} \mathrm{DBH}$. Tapping treatments follow Table $1{ }^{* *}$, treatments using $30 \%$ sulphuric acid; ${ }^{*}$, treatments using $5 \%$ sulphuric acid). The upper and lower portions of the box plot are the third and first quartiles, respectively, and the horizontal line is the median. Whiskers indicate the minimum and maximum values. Treatment G, the most intrusive method, was applied to very large trees only $(\geq 30.0 \mathrm{~cm} \mathrm{DBH})$.

$>60 \%$ more lansan than trees in the smallest size category (15.0-19.9 cm DBH). Irrespective of tree size or treatment, lansan yields increased over time (Fig. 2).

Resin production was also influenced by cutting method (Fig. 3). Trees produced more lansan when cuts were reopened instead of making new cuts elsewhere on the trunk, and treatments involving sulphuric acid solution consistently produced the largest yields. Across all size classes, treatment $\mathrm{D}$ (with $30 \%$ sulphuric acid) produced on average $134 \%$ more resin per tree per visit $(n=38$, mean lansan yield $=5.45$ $\left.\pm \mathrm{SD}_{3} .60 \mathrm{~g}\right)$ than the stimulant-free treatment $\mathrm{B}(\mathrm{n}=41$, mean yield $=2.33 \pm \mathrm{SD} 2.06 \mathrm{~g}, U=253.5, \mathrm{P}<0.0001$ ). Even large trees subjected to treatment $\mathrm{B}(25-41 \mathrm{~cm} \mathrm{DBH}$, mean yield $=2.81 \pm \mathrm{SD} 2.63 \mathrm{~g}$ ) could not match the productivity 
of smaller trees subjected to treatment $\mathrm{D}(15-24.9 \mathrm{~cm} \mathrm{DBH}$, mean yield $=4.40 \pm S D 2.30 \mathrm{~g}, U=92, \mathrm{P}=0.010$ ). Similarly, among the trees tapped using a narrow-faced cut, $84 \%$ more resin was produced by applying $30 \%$ sulphuric acid (treatment $\mathrm{F}$, mean yield $=6.52 \pm \mathrm{SD} 4.20 \mathrm{~g}$ ) than when no stimulant was used (treatment $\mathrm{E}$, mean yield $=3.54 \pm \mathrm{SD} 2.00$ $\mathrm{g}, U=328, \mathrm{P}<0.0001)$. Applying a weaker solution of $5 \%$ sulphuric acid was also effective, with treatment I producing $58 \%$ more resin than treatment $\mathrm{B}$ from trees in the same size categories.

\section{Tree growth and condition}

In the Barre de l'Isle, growth rates tended to be faster among smaller, younger trees, with a significant inverse correlation between a tree's $\mathrm{DBH}$ at the start of the study and its percentage increase in girth by July $2013(\mathrm{n}=310$, Pearson's correlation coefficient $(r)=-0.186, \mathrm{P}<0.001)$. Control trees exhibited the fastest growth rates during October 2010March 2012, when the other trees were tapped every 2 weeks (Fig. 4). However, when all of the study trees were remeasured 16 months after tapping ended, treatment categories that had shown poor growth during the experiment exhibited a strong growth spurt (Fig. 4). By July 2013, treatments $\mathrm{B}$ and $\mathrm{F}$ almost matched the control trees in net increase in girth.

Both during and after the tapping study there was no evidence that sulphuric acid affected growth rates. The growth of trees tapped using the same cutting method with $30 \%$ sulphuric acid (treatment $B$, mean $=4.34 \pm \mathrm{SD}_{3.14} \%$ ), for example, did not differ significantly from trees tapped without the acid (treatment $\mathrm{D}$, mean $=4.37 \pm \mathrm{SD}_{3.62} \%$, $U=790, \mathrm{P}=0.914$ ).

In Chassin, tree girth was measured in February 2011 and August 2013. Control trees grew almost twice as fast as the tapped trees and there was no significant difference between their percentage increase in girth $(n=36$, mean $=3.42 \pm S D$ $3.29 \%)$ and that of control trees in Barre de l'Isle $(n=40$, mean $=3.63 \pm \mathrm{SD} 2.81 \%, \quad U=789.5, \quad \mathrm{P}=0.473)$. However, the tapped trees in Chassin showed significantly poorer growth $(\mathrm{n}=38$, mean $=1.82 \pm \mathrm{SD} 2.47 \%)$ than trees tapped using narrow-face tapping in Barre de l'Isle (treatment E: $\mathrm{n}=38$, mean $=4.68 \pm$ SD 5.18\%, $U=1,147, \mathrm{P}<0.0001)$ during the same period. Treatment group $\mathrm{E}$ was chosen for comparison because many trees in Chassin exhibited signs of narrow-face tapping.

Ten months into the experimental study in Barre de l'Isle the untapped trees $(\mathrm{X})$ and treatment groups $\mathrm{H}$ and $\mathrm{I}$ had the best quality crowns, with mean scores of 4.0 or higher. No groups in Barre de l'Isle had mean scores $<3.6$, however, indicating most trees were in reasonable condition. Trees used by tappers in Chassin had thinner crowns by $2013(n=38$, mean score $=3.48 \pm \mathrm{SD} 0.85$ ) but were not in significantly

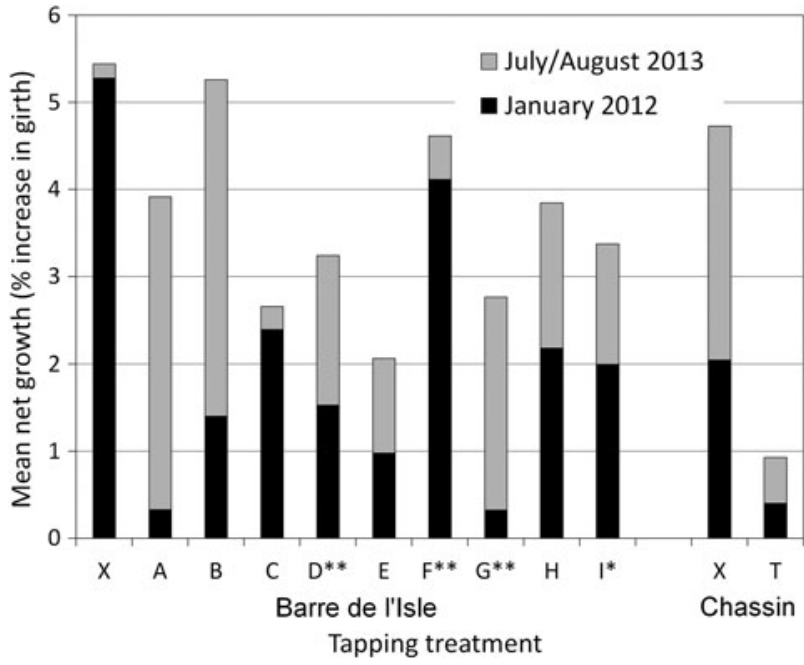

FIG. 4 Relationship between tapping method and tree growth during and after the experiment. Mean net growth from the start of the study to January 2012 (shortly before tapping ended), and mean net growth to July 2013 (16 months after tapping ended). Tree growth is presented as the percentage increase in DBH from the start of the study (October 2010 for control trees X and treatments $\mathrm{A}-\mathrm{G}$, and May 2011 for treatments $\mathrm{H}$ and I). Tapping treatments follow Table $1{ }^{* *}$, treatments using $30 \%$ sulphuric acid; ${ }^{*}$, treatments using $5 \%$ sulphuric acid). Only data from the largest tree size categories are shown (trees $\geq 25 \mathrm{~cm} \mathrm{DBH}$ when the study began). For comparison, trees in the same size categories in the Chassin study site grew by $4.73 \%$ (control trees, $\mathrm{X}$ ) and $0.93 \%$ (tapped trees, T) during February 2011-July/ August 2013 .

worse condition than the control trees in the same area ( $\mathrm{n}=36$, mean score $=3.67 \pm \mathrm{SD} 0.78, U=393, \mathrm{P}=0.398)$.

The trunks of many individuals in Barre de l'Isle, including the control trees, had at least one termite trail at the beginning of the study, but there was no net change in termite abundance by the end. Fungal infection was detected only rarely among the Barre de l'Isle trees. By the end of the study in Chassin, however, tapped trees had on average 3.5 times more termite trails (mean $=0.59 \pm$ SD 0.60 trails) than the control trees (mean $=0.18 \pm S D 0.37$ trails, $U=817$, $\mathrm{P}=0.003$ ) and significantly more fungal infections (mean = $0.242 \pm$ SD 0.44) than the controls (mean $=0.03 \pm$ SD 0.17 , $U=721.5, \mathrm{P}=0.009$ ).

Among other indicators of tree health (Table 1), we observed a general increase in the number of cavities during the study. The Barre de l'Isle trees subjected to wide-faced tapping $(G)$ exhibited the highest frequency, with a mean net increase of 0.56 cavities per tree during October 2010July 2013, whereas the control group had a mean net increase of only 0.06 cavities. In Chassin, tapped trees had approximately four times more cavities (mean $=0.42 \pm$ SD 0.64) than the control trees at the same site (mean $=0.09 \pm \mathrm{SD}$ 0.39, $U=601.5, \mathrm{P}=0.005$ ), and many more cavities than any of the Barre de l'Isle trees (Fig. 5). 


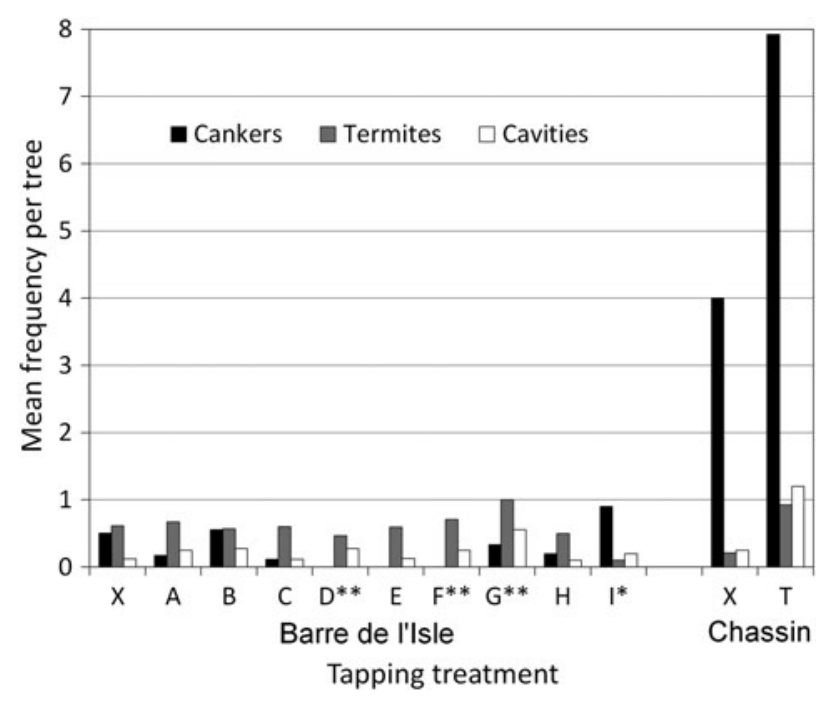

FIG. 5 Relationship between tapping method and the mean numbers of cankers (protruding by $\geq 2 \mathrm{~cm}$ ), termite trails and cavities by July/August 2013 (16 months after the tapping experiment ended in Barre de l'Isle). Tapping treatments follow Table $1{ }^{* *}$, treatments using $30 \%$ sulphuric acid; ${ }^{*}$, treatments using $5 \%$ sulphuric acid). Only data from the largest tree size category $(\geq 25 \mathrm{~cm} \mathrm{DBH})$ are shown.

There was no clear relationship between treatment and canker development among the Barre de l'Isle trees (Fig. 5) but the tapped trees in Chassin bore more than twice as many cankers (mean $=7.75 \pm \mathrm{SD} 5.31$ cankers per tree) as non-tapped trees (mean $=3.05 \pm \mathrm{SD} 4.73$ ), and over seven times more cankers than any of the Barre de l'Isle groups (Fig. 5). During the study the Chassin trees had higher rates of developing new cankers (tapped trees: mean net increase of 0.38 cankers per tree per month; control trees: mean net increase of 0.11 cankers per tree per month) than any treatment groups in Barre de l'Isle.

Applying sulphuric acid solution had no perceptible effect on tree condition at the Barre de l'Isle site. Trees tapped with $30 \%$ sulphuric acid stimulant (D and $F ; n=76)$ and without (treatments $\mathrm{A}, \mathrm{B}, \mathrm{C}$ and $\mathrm{E} ; \mathrm{n}=154$ ) did not differ significantly in growth rates $(U=5,774, \mathrm{P}=0.871)$, crown form $(U=5,578, \mathrm{P}=0.553)$, cankers $(U=5,713, \mathrm{P}=0.745)$, cavities $\quad(U=5,733, \quad \mathrm{P}=0.517), \quad$ termites $\quad(U=6,409$, $\mathrm{P}=0.177)$ or fungi $(U=5,769, \mathrm{P}=0.509)$. The only significant difference was that sulphuric acid treatments resulted in significantly more resin $(U=1,839, \mathrm{P}<0.0001)$.

\section{Tree mortality}

In November 2010, shortly after this study began, 12 study trees at the Barre de l'Isle site died during Hurricane Tomas and were replaced with 12 more trees in the same vicinity. Since then 29 other trees in the study group were found dead or broken. These were distributed evenly across the various treatment groups, and three deaths were recorded in the control group. Our data do not reveal any clear relationship between tree mortality and the treatments received but the 20 trees that died or snapped were significantly smaller (mean DBH $=21.31 \pm \mathrm{SD} 5.24 \mathrm{~cm}$ ) than the trees that survived (mean $\mathrm{DBH}=26.48 \pm \mathrm{SD} 7.89 \mathrm{~cm}$, $U=4,065, \mathrm{P}<0.003$ ). A partial Mantel test found no significant association between mortality rates and the treatment used, the quantity of lansan produced, or the growth rates or frequency of cankers or cavities, but there was a highly significant association with the number of termite trails on the trunk $(\mathrm{P}=0.0012)$.

In Chassin Forest, trees used by local tappers had a significantly higher rate of mortality (mean mortality rate $=$ $0.15 \pm$ SD 0.37) than the untouched trees between the start of the study and August 2013 (mean $=0.00, U=810, \mathrm{P}=0.015$ ). The trees that died did not differ significantly from the surviving trees in Chassin in terms of DBH or frequency of termites, cavities, fungi or cankers.

\section{Consumer survey}

Seven churches in the towns of Babonneau, La-Resource, Desruisseaux, Gros-Islet, La Clery, Micoud and Anse La Raye carried out blind tests of lansan that had been harvested using 30\% sulphuric acid and lansan harvested without any stimulant. The respondents expressed a high level of satisfaction with both samples, and no significant differences were detected in their perceptions of the resin's burning characteristics, smoke, scent or overall quality (Table 3 ). All but one affirmed they would be willing to pay more for good-quality lansan.

\section{Discussion}

Identifying more productive and sustainable methods of extracting resin

By subjecting 372 trees to more than a dozen treatments, the field study provided useful insights into the ecology of lansan trees and their response to tapping. Resin yields were increased by tapping the same individuals repeatedly, tapping larger trees, reopening cuts instead of making new ones elsewhere on the trunk, using narrow-faced or broad-faced tapping and, most strikingly, applying a solution of sulphuric acid. Even the weakest (5\%) solution of sulphuric acid boosted resin production significantly.

In other parts of the world sulphuric acid is commonly used as a stimulant for increasing commercial resin production (e.g. spraying a $50 \%$ solution of sulphuric acid on fresh cuts on Pinus palustris raises resin production by $31-$ $36 \%$ by increasing resin flux and extending the extrusion period; Panda, 2008). Despite using weaker concentrations 
TABLE 3 Consumer scores for resin produced with and without stimulant, with Wilcoxon V and statistical significance. These are the mean scores from seven churches in Saint Lucia, each of which was subjected to a blind test of two samples of lansan, one produced without stimulant and one produced using 30\% sulphuric acid. Variables were scored by the priests on a scale of $1-5$, with 5 being the most satisfactory. None of the tests was statistically significant at $\mathrm{P}<0.05$.

\begin{tabular}{|c|c|c|c|c|}
\hline Variable & $\begin{array}{l}\text { Lansan produced } \\
\text { with stimulant }\end{array}$ & $\begin{array}{l}\text { Lansan produced } \\
\text { without stimulant }\end{array}$ & Wilcoxon V & $\mathrm{P}$ \\
\hline Burning behaviour & 4.29 & 4.14 & 6.00 & 0.766 \\
\hline Rise of smoke & 4.29 & 4.43 & 6.00 & 0.850 \\
\hline Scent & 3.89 & 4.14 & 13.50 & 0.589 \\
\hline Overall quality & 3.86 & 4.00 & 9.00 & 0.766 \\
\hline
\end{tabular}

of sulphuric acid, our study of $P$. attenuatum showed even more striking results, with resin yields increased by $134 \%$ with $30 \%$ sulphuric acid solution and by $58 \%$ with $5 \%$ sulphuric acid. Instead of spraying the exposed cut, however, many commercial resin collectors apply pastes containing sulphuric acid and 2-chloroethylphosphonic acid (CEPA; Reynolds \& Kossuth, 1984). Rodrigues et al. (2008) doubled resin yields from Pinus elliottii by using a commercial paste of $20 \%$ sulphuric acid and $3.5 \%$ CEPA but remarked on the high cost of CEPA. It would be interesting to test commercial pastes and other stimulants on lansan trees but our findings suggest a weak solution (5-10\%) of sulphuric acid alone has a sufficiently potent effect. It is also available locally and is affordable.

Our experiment in the Barre de l'Isle Forest confirmed lansan trees can maintain such enhanced yields for at least 17 months of continuous exploitation. Although even the mildest forms of tapping tend to slow tree growth, promote canker development and may result in a poorer crown, tree growth and condition were unaffected by the sulphuric acid solution. The most damaging methods tested entailed deeper cuts, narrow-faced tapping and wide-faced tapping, which are common practices among local tappers but tend to create cavities in the heartwood. After our tapping experiment ended, the lansan trees demonstrated an extraordinary spurt in growth, which suggests factoring in rest periods could be an effective way of enabling lansan trees to cope with exploitation.

Despite our efforts to replicate methods used by tappers in Saint Lucia, the trees at the Barre de l'Isle experimental site remained in better condition than those in Chassin Forest. Trees exploited by local tappers using their customary methods exhibited high rates of decay, with more termites, fungi, cankers and cavities than the non-tapped trees, and relatively high mortality rates. Despite selecting trees that appeared healthy at the start of the study, six of the 38 tapped trees had died by August 2013, a mortality rate of $6.3 \%$ per year. When trunks snapped, this usually occurred around the part of the trunk that had been tapped. Unexpectedly, even the untapped (control) trees in Chassin exhibited high frequencies of cankers, which may indicate infectious fungi or bacteria spreading from the many severely tapped and dying trees in this area. Thus, we infer poor tapping practices endanger not only the tapped trees but the untapped trees around them.

These findings suggest that $P$. attenuatum are fragile trees that can be debilitated rapidly and killed by intensive tapping. The customary strategies employed by tappers in Saint Lucia are damaging, which is perhaps a 'tragedy of the commons' (Hardin, 1968). Because tappers enter forest reserves illegally and lack individual rights over the trees it is in their interest to extract as much resin as quickly as possible on every visit, even from trees that are obviously immature or sick. With more Saint Lucians turning to the forests for income, lansan trees are in danger of becoming locally extinct.

Our findings from Barre de l'Isle show that with the aid of a stimulant tappers can harvest more lansan by using fewer cuts, thereby presenting less risk to the trees. To put our findings in context, if 1,00o large lansan trees $(>20$ $\mathrm{cm} \mathrm{DBH}$ ) were tapped every 2 weeks for 12 months using the standard same-cut method with $30 \%$ sulphuric acid (treatment D) they would yield at least $152 \mathrm{~kg}$ pure resin (dry mass), which could be sold raw for at least USD 2,460. Without stimulant the same 1,000 trees would yield on average only $49 \mathrm{~kg}$ (USD 790). These are conservative estimates of price because lansan is sold locally by volume rather than mass, and bags of resin are often bulked out with bark. Pure lansan should command higher prices and there is scope to add more value by processing "Saint Lucia frankincense" into incense sticks, soaps and other merchandise for local people, churches and tourists. We lack accurate measures of the quantity of resin collected illegally by tappers in Chassin and other forest reserves, but visual inspections of tapped trees suggest they do not typically generate as much resin as we achieved using the stimulant. Unlike Protium resin harvesters in South America (Plowden, 2001), Saint Lucian tappers are not competing for the resin with bees or other wild animals.

The prospect of each tapper locating and harvesting 1,000 or more mature trees sustainably is realistic given the locally high density of lansan trees in Saint Lucia. Forest plot data from Graveson (2009) indicate a mean density of c. 50 lansan trees (individuals $\geq 5 \mathrm{~cm} \mathrm{DBH}$ ) per ha in the lower montane rainforest. Using a larger number of plots, Toussaint (2009) found a mean of 22.33 stems of 
lansan trees $\geq 10 \mathrm{~cm} \mathrm{DBH}$ per ha in the forest reserves. Extrapolating from these data gives an estimated total of 312,000 lansan trees $\geq 10 \mathrm{~cm} \mathrm{DBH}$, of which c. 100,000125,000 are $\geq 20 \mathrm{~cm} \mathrm{DBH}$ (our conservatively recommended minimum threshold for tapping, see below) in the forest reserve.

\section{A new framework for harvesting lansan sustainably}

Our discovery that resin can be harvested using a method that is both more productive and less damaging to the trees than customary practices is an important breakthrough. Drawing on our findings and consultations with forestry officials, tappers and traders, a national management plan for Saint Lucia's lansan trees has been developed (Forestry Department, 2014). This sets out a new framework and protocols to conserve the wild lansan trees while also enabling people to benefit from collecting, trading and using their resin. The plan entails licensing tappers under the Forest Act and the 2008 Forest (Timber and Non Timber Products) Regulations and granting individual rights to harvest lansan in designated areas of the forest reserves. Every tapper will have harvesting rights in a demarcated area of forest containing a high density of mature lansan trees of harvestable size ( $\geq 20 \mathrm{~cm} \mathrm{DBH})$. Tappers must use only the standard same-cut method of tapping, to minimize risk to the trees, and will be trained and provided with readymixed $5-10 \%$ solution of sulphuric acid to achieve high yields $(30 \%$ sulphuric acid is more potent but also more hazardous for tappers to transport and use).

The new management strategy incorporates a number of safeguards for the lansan tree population, including routine monitoring of the lansan forest coupes by the Forestry Department and prohibiting tapping trees $<20 \mathrm{~cm} \mathrm{DBH}$, thereby allowing smaller mature trees to grow and reproduce without interference (flowering and fruiting have been recorded in lansan trees as small as $4 \mathrm{~cm} \mathrm{DBH}$; Rollet, 2010; Forestry Department, 2014). Another precaution is to rotate the coupes to allow trees to recuperate after being tapped for 1 or 2 years. We found that even after 17 months of tapping, most lansan trees recover quickly and make up for lost growth. Finally, to further bolster the country's wild stocks, the Forestry Department has begun cultivating lansan trees in its nurseries for use in reforestation and slope stabilization projects.

The management plan is already being put into action with a pilot group of tappers from Chassin and Dennery villages. The more professional tappers genuinely welcome better regulation of their industry:

Many tappers have expressed strong concern about conservation of the tree and observed what they considered unscrupulous harvesters who do not care about the health of the trees ... They strongly expressed the need for the issuance of licenses to those harvesters who have a vested interest in lansan and who are concerned with its conservation. They also expressed the need for enforcement of laws to protect the forest resource and stiffer penalties for unscrupulous harvesters. (Toussaint, 2009)

By granting them their own coupes and legitimizing their livelihoods, tappers will feel more empowered to look after the forests and will be willing to assist forestry staff by reporting unlicensed tappers and other illegal activities. As the licensing scheme is introduced nationwide an outreach campaign will urge lansan traders, churches and other consumers to buy incense from licensed tappers only. Preliminary discussions indicate traders and churches are willing to comply.

A similar strategy to support livelihoods and forest conservation could feasibly be adopted by tappers and regulatory authorities in other lansan tree range states. Forestry officers in Dominica, Martinique and Guadeloupe have expressed interest in this project, and study tours to Saint Lucia are planned for 2015. Comparable efforts are underway in other countries to develop sustainable resin programmes for other tree species, to support local livelihoods, for example in Guatemala (Neels, 2000), the Philippines (Ella, 2003), Cambodia (Tola \& McKenney, 2003; Neang, 2009), India (Nair, 2003) and Ethiopia (Lemenih \& Kassa, 2011). Although most programmes have traditional extraction methods at their core, our study illustrates the danger of assuming these are the most appropriate methods for achieving high yields or low impacts (Peters, 1994). Adapting our experimental approach of testing and evaluating alternative methods, coupled with consulting local tappers and buyers, could help other projects discover better ways of extracting tree resin, even from species unrelated to $P$. attenuatum.

To conclude, Saint Lucia now has good prospects of halting the destruction of lansan trees, meeting the demands of churches and other consumers, and ensuring its tappers and traders continue to profit from this important resource. The new management framework (Forestry Department, 2014) has a number of advantages, including the following: lansan trees are still locally abundant; most of their range is protected and under no other threat; a regulatory system already exists for licensing collection of forest products; tappers are willing to engage in improving and legalizing their industry; and resin can be harvested successfully without debilitating wild trees. This satisfies many of the criteria identified by Newton (2008) for achieving tree conservation through sustainable use. As with any new management regime for a globally threatened species, however, it is important to monitor its implementation and outcomes, and to be prepared to make adjustments as new information arises.

\section{Acknowledgements}

For assistance with data collection we thank colleagues from the Forestry Department, including Aloysius Charles, Sean 
Francois, Lenn Isidore, Odetta James, Marthas Peter, Virginie Sealys, Margaret Severin and Vincent Ernest, and volunteers contracted by Durrell Wildlife Conservation Trust, including Imogene Aylwin, Michael Ball, Benjamin Barca, Tristan Chan, Nick Condie, Karin Crofts, Carolla Dalmeier, Twyla Holland, Barbara Schaeffer, April Tyror, Nathan Wood and Robert Williams. We also thank the churches that participated in the consumer survey. This research was supported financially by the Global Trees Campaign, the Franklinia Foundation and the Flagship Species Fund. We thank two anonymous reviewers for constructive comments.

\section{References}

Ahmad, S. (2003) Good harvesting practices for non-timber forest products and the patent regime. Proceedings of the XII World Forestry Congress, 21-28 September 2003, Quebec, Canada.

Akter, S., Islam, M.T., Zulkefeli, M. \& Khan, S.I. (2013) Agarwood production-a multidisciplinary field to be explored in Bangladesh. International Journal of Pharmaceutical and Life Sciences, 2, 22-32.

Ali, A.H., FADL, K.E.M. \& ADAM, I.M. (2009) Effect of position of tapping, tree stem diameter and tapping tools on frankincense yield of Boswellia papyrifera in South Kordofan State, Sudan. Forests, Trees and Livelihoods, 19, 19-26.

Arnold, J.E.M. \& Ruíz-Pérez, M. (2001) Can non-timber forest products match tropical forest conservation and development objectives? Ecological Economics, 39, 437-447.

Broome, R., Sabir, K. \& Carrington, S. (2007) Plants of the Eastern Caribbean. Http://ecflora.cavehill.uwi.edu/index.html [accessed 10 December 2014].

CCA (Caribbean Conservation Association) (1991) Country Environmental Profile: Saint Lucia. Caribbean Conservation Association, St. Michael, Barbados.

Coad, L., Campbell, A., Miles, L. \& Humphries, K. (2008) The Costs and Benefits of Forest Protected Areas for Local Livelihoods: A Review of the Current Literature. Working Paper. UNEP World Conservation Monitoring Centre, Cambridge, UK.

Collar, N.J., Gonzaga, L.P., Krabbe, N., Madroño Nieto, A., Naranjo, L.G., Parker, T.A. \& Wege, D.C. (1992) Threatened Birds of the Americas: The ICBP/IUCN Red Data Book. International Council for Bird Preservation, Cambridge, UK.

Daltry, J.C. (2009) Biodiversity Assessment of Saint Lucia's Forests, With Management Recommendations. Technical Report No. 10 to the National Forest Demarcation and Bio-Physical Resource Inventory Project, FCG International Ltd, Helsinki, Finland.

EllA, A.B. (2003) Improved tapping of almaciga tree for sustained resin yield. In Seminar Proceedings: Harvesting of Non-Wood Forest Products, pp. 405-406. Joint FAO/ECE/ILO Committee on Forest Technology, Management and Training, Food and Agriculture Organization of the United Nations, Rome, Italy.

Forestry Department (2014) Management Plan for Saint Lucian Lansan. Forestry Department, Union, Saint Lucia.

Graveson, R. (2009) The Classification of the Vegetation of Saint Lucia. Technical Report No. 3 to the National Forest Demarcation and Bio-Physical Resource Inventory Project, FCG International Ltd, Helsinki, Finland.

Hardin, G. (1968) The tragedy of the commons. Science, 162, 12431248.

Higgins-Zogib, L., Dudley, N., Mansourian, S. \& Suksuwan, S. (2010) Safety net: protected areas contributing to human well-being.
In Arguments for Protected Areas: Multiple Benefits for Conservation and Use (eds S. Stolton \& N. Dudley), pp. 121-144. Earthscan, Washington, DC, USA.

Howard, R.A. (1988) Flora of the Lesser Antilles, Leeward and Windward Islands. Arnold Arboretum, Harvard University, Jamaica Plain, USA.

IUCN (2014) IUCN Red List of Threatened Species v. 2014.3. Http:// www.iucnredlist.org [accessed 8 December 2014].

Johnson, R.N. (1998) Multiple products, community forestry and contract design: the case of timber harvesting and resin tapping in Honduras. Journal of Forest Economics, 4, 127-146.

Langenheim, J.H. (2003) Plant Resins: Chemistry, Evolution, Ecology and Ethnobotany. Timber Press, Portland, USA.

Legendre, P. \& Fortin, M. (1989) Spatial pattern and ecological analysis. Vegetatio, $80,107-138$.

Lemenih, M. \& Kassa, H. (eds) (2011) Opportunities and Challenges for Sustainable Production and Marketing of Gums and Resins in Ethiopia. Centre for International Forestry Research, Bogor, Indonesia.

Longwood, F.R. (1962) Present and Potential Commercial Timbers of the Caribbean with Special Reference to the West Indies, the Guianas and British Honduras. Agriculture Handbook No. 207, Forest Service, U.S. Department of Agriculture, Washington, DC, USA.

Moran, M.D. (2003) Arguments for rejecting the sequential Bonferroni in ecological studies. Oikos, 100, 403-405.

Morton, M. (2009) A Survey of Wildlife Use on Saint Lucia. Technical Report No. 7 to the National Forest Demarcation and Bio-Physical Resource Inventory Project, FCG International Ltd, Helsinki, Finland.

NAIR, B. (2003) Sustainable utilization of gum and resin by improved tapping technique in some species. In Seminar Proceedings: Harvesting of Non-Wood Forest Products, pp. 293-305. Joint FAO/ ECE/ILO Committee on Forest Technology, Management and Training, Food and Agriculture Organization of the United Nations, Rome, Italy.

Ndangalasi, H.J., Bitariho, R. \& Dovie, D.B.K. (2007) Harvesting of non-timber forest products and implications for conservation in two montane forests of East Africa. Biological Conservation, 134, 242-250.

NeAng, T. (2009) Liquid resin tapping by local people in Phnom Samkos Wildlife Sanctuary. Cambodian Journal of Natural History, 2009, 16-25.

NeELS, S. (200o) Yield, sustainable harvest and cultural uses of resin from the copal tree (Protium copra: Burseraceae) in the Carmelita Community Forest Concession, Petén, Guatemala. B.Sci.Ag thesis. University of British Columbia, Vancouver, Canada.

Newton, A.C. (2008) Conservation of tree species through sustainable use: how can it be achieved in practice? Oryx, 42, 195-205.

Newton, P., Watkinson, A.R. \& Peres, C.A. (2011) Determinants of yield in a non-timber forest product: Copaifera oleoresin in Amazonian extractive reserves. Forest Ecology and Management, 261, 255-264.

Palli, F. (undated) Arbres de la Martinique: Les Arbres de la Forêt Martiniquaise-Répertoire Complet. Http://www.potomitan.info/ divers/arbres.html [accessed 25 March 2013].

Panda, H. (2008) Handbook on Oleoresin and Pine Chemicals (Rosin, Terpene Derivatives, Tall Oil, Resin \& Dimer Acids). Asia Pacific Business Press, Delhi, India.

Peters, C.M. (1994) Sustainable Harvest of Non-Timber Plant Resources in Tropical Moist Forest: An Ecological Primer. Biodiversity Support Program, World Wildlife Fund, Washington, DC, USA. 
Peters, C.M., Gentry, A.H. \& Mendelsohn, R.O. (1989) Valuation of an Amazonian rainforest. Nature, 339, 655-656.

Plowden, J.C. (2001) The ecology, management and marketing of non-timber forest products in the Alto Rio Guamá indigenous reserve (eastern Brazilian Amazon). PhD thesis. Pennsylvania State University, State College, USA.

Questel, A. (1951) Géographie Générale de la Guadeloupe et Dépendences. Volume I, La Flore de la Guadeloupe (Antilles Francaises). Paul Lechevalier, Paris, France.

Reynolds, R.D. \& Kossuth, S.V. (1984) CEPA in sulfuric acid paste increases oleoresin yields. Southern Journal of Applied Forestry, 8, 168-172.

Rice, W.R. (1989) Analyzing tables of statistical tests. Evolution, 43, 223-225.

Rodrigues, K.C.S., Azevedo, P.C.N., Sobreiro, L.E., Pelissari, P. \& Fett-Neto, A.G. (2008) Oleoresin yield of Pinus elliottii plantations in a subtropical climate: effect of tree diameter, wound shape and concentration of active adjuvants in resin stimulating paste. Industrial Crops and Products, 27, 322-327.

Rollet, B. (2010) Arbres des Petites Antilles. Tome 2: Description et Espèces. Office National des Forêts, Direction Régionale de Guadeloupe, Basse-Terre, Guadeloupe.

Schwartzman, S., Moreira, A. \& Nepstad, D. (200o) Rethinking tropical forest conservation: perils in parks. Conservation Biology, 14, 1351-1357.

Slane, V. (1987) Uses of Plants in St Lucia. Unpublished report.

Stanley, D., Voeks, R. \& ShORT, L. (2012) Is non-timber forest product harvest sustainable in the less developed world? A systematic review of the recent economic and ecological literature. Ethnobiology and Conservation, 1, 9.

Synot T, T.J. (1979) A Manual of Permanent Plot Procedures for Tropical Rainforests. Tropical Forestry Paper No. 14, Commonwealth Forestry Institute, University of Oxford, Oxford, UK.

Tadesse, W., Feleke, S. \& Eshete, T. (2004) Comparative study of traditional and new tapping methods on frankincense yield of
Boswellia papyirifera. Ethiopian Journal of Natural Resources, 6, 287-299.

Tola, P. \& McKenney, B. (2003) Trading Forest Products in Cambodia: Challenges, Threats, and Opportunities for Resin. Working Paper 28, Cambodian Development Resource Institute and the Cambodian NTFP Working Group, Phnom Penh, Cambodia.

Toussaint, A. (2009) Assessing the sustainable management and production of l'ansan, Protium attenuatum incense, in Saint Lucia. MSc thesis. Universidad Internacional de Andalucia, Seville, Spain.

Tsoumis, G. (1992) Harvesting Forest Products. Stobart Davies,

Hertford, UK.

VAn Eynde, K. (2009) Forest Management Guidelines. Technical Report No. 8 to the National Forest Demarcation and Bio-Physical Resource Inventory Project, FCG International Ltd, Helsinki, Finland.

WCMC (World Conservation Monitoring Centre) (1998) Protium attenuatum. In IUCN Red List of Threatened Species v. 2013.2. Http://www.iucnredlist.org/details/full/33993/o [accessed 10 April 2014].

\section{Biographical sketches}

Jennifer Daltry has spent more than 20 years developing biodiversity conservation programmes with NGOs and governments in the Caribbean, tropical Asia and Eurasia, often focusing on lesser known globally threatened species. Alfred Prospere and Adams TOUSSAINT are foresters with keen interests in the conservation and sustainable use of Saint Lucia's rich biodiversity. JANA GENGELBACH is a graduate in International Forest Ecosystem Management and takes great interest in natural resource management and public participation. Matthew Morton has worked on wildlife research and conservation projects with in-country partners in the Eastern Caribbean since 1993 and has been based in Saint Lucia for over 12 years. 